\section{COVARIATES OF NURSES' MANAGEMENT OF PAIN IN CHILDREN}

A. Stuer ${ }^{1}$, I.V. Gorp ${ }^{1,2}$, K. Allegaert ${ }^{3}$

${ }^{1}$ Department of Health Care, KHKempen University College, Turnhout, '2Department of Paediatrics, ${ }^{3}$ Neonatal Intensive Care Unit, University Hospitals Leuven, Leuven, Belgium

Introduction: Effective implementation of an evidence based pain policy for children is affected by nurses' knowledge of, attitudes towards and selfefficacy. Since nurses from different departments and with different levels of education manage pain in children, we evaluated the impact of the nursing ward and educational level on the management of paediatric pain.

Methods: Nurses working in paediatric wards or emergency departments of 16 regional or academic hospitals in Flanders, Belgium were invited to participate. A validated multiple choice questionnaire (Pediatric Nurses' Knowlegde and Attitudes regarding Pain Survey, PNKAS) [1] was used to assess knowledge and attitudes while selfefficacy for paediatric pain was assessed based on the Nurses Self Efficacy in Managing Children's Pain questionnaire [2].

Results: Questionnaires from 550 nurses were collected. Deficits in knowledge, attitudes and self-efficacy of nurses were documented. Nurses' knowledge deficits are mainly situated within the area of drug prescription. Compared to nurses from emergency department, nurses from pediatric wards have significantly higher scores on self-efficacy, but not on knowledge and attitudes. As for knowledge and attitudes, nurses with an educational level higher than bachelor score better than nurses with a lower level of education. However, this is not the case as far as self-efficacy is concerned.

Conclusions: Nursing ward and educational level influence nurses' management of paediatric pain. This should be taken in consideration during teaching and subsequent implementation of an evidence based paediatic pain policy.[1] Mannworren et al, Pediatr Nurs 2000[2] Chiang et al, J Pain Sympt Manag 2006

\section{PASSIVE DISTRACTION IS THE ONLY DETERMINANT OF PAIN DURING VENOUS BLOOD SAMPLING IN SCHOOL CHILDREN IN AN OUTPATIENT CLINIC SETTING}

\author{
J. Nijs ${ }^{1}$, A. Stuer ${ }^{2}$, I.V. Gorp ${ }^{1,2}$, K. Allegaert ${ }^{3}$
}

${ }^{1}$ Department of Paediatrics, University Hospitals

Leuven, Leuven, ${ }^{2}$ Department of Health Care, KHKempen University College, Turnhout, ${ }^{3}$ Neonatal Intensive Care Unit, University Hospitals Leuven, Leuven, Belgium

Introduction: Non-pharmacological interventions can be used to minimize discomfort, but data on the impact of non-pharmacological interventions on procedural pain in children are limited. We therefore evaluated the impact of distraction (TV watching) during elective venipuncture in children.

Methods: 58 children (6-12 years) were asked to document pain perception (VASc score, cm) during venipuncture. Parents (VASp) and nurses (VASn) were also asked to quantify procedural pain as perceived by them. In 31 cases, the child was stimulated to watch a movie chosen by the child (passive distraction group). Characteristics and VASc scores between groups were compared (unpaired) and risk factors for increased VASc score $(>4)$ were entered in a multiple logistic model, interrater agreement (kappa) was used to compare VASc with VASp and VASn.

Results: Median VASc was 2.2 (range 0-7.3), 11/58 children reported VASc $>4$ (2 in distraction group). Median VASc was lower in the distraction group (1.5 to $3.1, p<0.001)$. Gender, age nor earlier blood sampling (last year) determined VASc. In a logistic regression model, passive distraction was the only protective factor (OR $7.25,95 \% \mathrm{Cl} 1.4$ to 37.4 ) to avoid VASc $>4$. Median VASp and VASn were 2.5 and 2. Although correlations with VASc were 0.74 and 0.53 , kappa-scores were fair (0.23 and 0.31).

Conclusions: Although the median difference (1.5 vs 3.1) in VASc during distraction is limited, it does result in a significant decrease in VASc $>4$ observations. Interrater agreement was fair, confirming that hetero-evaluation of pain remains poor. 